\title{
Deflationary Pluralism about Motivating Reasons ${ }^{1}$
}

\author{
Daniel Fogal \\ Uppsala University
}

\section{Introduction}

Let's begin with the seemingly obvious: We believe lots of things, and we believe things for reasons. What we believe often changes-we gain and lose beliefs over time-as do our reasons for believing-we revise and update our beliefs in response to new information. However, we don't always believe for good reasons. Instead, we sometimes believe for bad reasons-reasons that are defective in some way, whether in kind, quality, quantity, or strength. But at least in general, when we believe for good reasons, we thereby put ourselves in a position to know. The world is mostly responsible for the rest.

Although it's hard to deny the appeal of such intuitive reflections, talk of reasons for believing and believing for reasons can be confusing. That's because there are several distinct strains in such talk, and failing to be sensitive to their differences-as well as similarities and relationship to each other-can easily lead one astray. It can also make it easy to engage in verbal disputes, or construct arguments whose plausibility or significance is merely apparent. This paper will be concerned with one such dispute: over the nature of so-called "motivating" reasons. Motivating reasons are standardly characterized as the reasons for which or on the basis of which we do things - where 'doing things' includes performing actions as well as forming (and sustaining) beliefs, intentions, and the like. Although special attention will be paid to cases involving belief, much of the paper will be concerned with motivating reasons more generally.

Motivating reasons are standardly distinguished from the reasons there are to do things, also known as 'normative' reasons. The class of motivating reasons is usually thought to be important because such reasons provide a distinctive kind of 'rationalizing' explanation of our actions and attitudes, rendering them intelligible. They are also commonly thought to play an important role in determining whether an action or attitude is 'properly based' or 'well-grounded', and hence apt candidates for properties such as being creditworthy as well as being rational or justified. The idea is that in order to (e.g.) deserve credit for doing the right thing,

\footnotetext{
${ }^{1}$ Forthcoming in Veli Mitova (ed.) The Factive Turn in Epistemology. Thanks to Richard Lawrence, Errol Lord, Susanne Mantel, Caleb Perl, Daniel Whiting, an anonymous referee, and especially Olle Risberg for helpful comments that led to substantial improvements.
} 
it's not enough to just do the right thing-one also has to do it for the right reasons. The same goes for having justified or rationally held beliefs, intentions, and the like-one's attitudes have to be properly based, or well-grounded. ${ }^{2}$

There is controversy over what exactly motivating reasons are, however. To illustrate: suppose that I'm curious what time the Lakers are playing, and check the newspaper to find out. I see the headline: 'The NBA Finals: Lakers vs. Celtics8:30 PM EST'. Taking the newspaper to be reliable, I form the belief that the Lakers play at 8:30 PM. Question: what is my reason for so believing? Is it the fact-or, perhaps, the proposition - that the newspaper said so? Or is it my belief that newspaper said so, or perhaps instead something about my visual experience? Factualism is the view that motivating reasons are (generally non-mental) facts, propositionalism that they are propositions, and statism that they are mental states, or facts about such.

When faced with the question concerning my reason for believing the Lakers play at 8:30 PM, one may wonder: do we really have to choose? One may suspect not-that we're being presented with something akin to a false dilemma. As we'll see, my sympathies are with this skeptical view. But even assuming I'm wrong, we face another question: how do we decide between competing answers, and in particular whether motivating reasons are facts, propositions, states, or something else? To date, much of the debate has focused on a range of broadly linguistic considerations concerning what it is and isn't appropriate to say about various cases using certain ordinary locutions. The default-and usually implicit-assumption seems to be that our ordinary talk concerning what is or isn't someone's reason for doing (believing, etc.) something directly and reliably tracks something of philosophical interest, and as a result should tightly constrain our theorizing. More than that, however, the assumption is that such talk reliably tracks some (kind of) thing, and that as a result it makes sense to ask what that thing is.

One might have doubts about such assumptions, however, as well as the underlying methodology of relying heavily on the propriety of certain ordinary locutions as a guide when engaging in substantive philosophical theorizing. Once again my sympathies are with the skeptical view. Although ordinary language has many virtues, reliably carving nature at its joints isn't one of them. Hence the need for (well-motivated) technical terms-among other things-in better understanding and representing the relevant domain of inquiry. Although this general methodological perspective is commonplace, the extent to which it applies to various subdisciplines and debates in philosophy remains a matter of

\footnotetext{
${ }^{2}$ For additional discussion-as well as some underappreciated complexities—see Lord (forthcoming), Chapters 5-6.
} 
contention. Nonetheless, I think it's prudent to at least allow for the possibility that the things (objects, properties, relations, etc.) of central philosophical interest in a given domain fail to be reliably tracked by any particular bit of ordinary languageat least prior to regimentation, and hence conversion into a technical term. One way of doing so is to use a non-ordinary language term or expression to pick out whatever the phenomenon of interest happens to be. It then becomes a further question whether the technical term is co-extensive with any expression of ordinary language, a question that can only be answered after careful investigation of (the uses of) both.

This sort of approach in epistemology is adopted by Pryor (2014), for instance. In defending the existence of immediately justified beliefs, he writes:

Recall that a "justification maker" is defined to be whatever makes it epistemically appropriate for you to believe some propositions rather than others. We should be open to the possibility that terms like "evidence" and "reasons" do not express exactly that notion. They may express different, or more specific, notions. (214)

Although this approach is common throughout philosophy, it's hardly universal, and all too often methodological unclarity runs rampant. ${ }^{3}$ Debates about normative and motivating reasons - and the roles they're supposed to play-are no exception.

One way of making progress, I think, is to clearly distinguish between the use of 'reason(s)' in its ordinary sense (or, rather, senses) and the use of 'reason(s)' in some other, more technical sense (or senses). As we'll see below, I think all ordinary claims involving the count noun 'reason(s)' are essentially explanatory in nature, where the relevant notion of explanation is partly pragmatic. Very roughly, we can think of reasons in the ordinary sense as providing answers to why-questions. ${ }^{4}$

\footnotetext{
${ }^{3}$ An excellent case study is causation: see Paul and Hall (2013; chaps. 1-2).

${ }^{4}$ The view that reasons-and explanations more generally-are answers to why-questions is associated with Hempel (1965), Bromberger (1966) and van Fraassen (1980). As Jenkins (2008) notes, however, although some reasons may be naturally described as answers to why-questions, others are more naturally described as things that are cited in answers. Like Jenkins, I count both as things that (at least help) provide answers to why-questions. I also follow Jenkins in operating with "determinedly informal notions of a 'why'-question and an answer to a 'why'-question", since it seems "likely that our everyday notions of explanation [and reasons] are vague, complex, and unlikely to succumb to any straightforward formalization" (71). It is these "everyday, fuzzy, notions" that I-like Jenkins-seek to illuminate. I therefore won't be directly engaging with the large and illuminating literature on questions in formal semantics (cf. Cross and Roelofsen 2016), as well as other ways in which information can be structured in a discourse (cf. Roberts 2012a,b).
} 
(The answers may be actual or possible, partial or full, etc.; I'll be ignoring such complexities.) Why-questions are standardly entertained and investigated in a particular context, by particular people, people who in asking the question already possess, and thus presuppose, a huge amount of the background information. A successful answer to such a why-question will be one that helps make sense of the phenomenon being asked about, or render it intelligible, given the background information already possessed by the inquirer. Slightly more fully, following Woodward $(2014, \$ 6.1)$ we can say that an explanation in the pragmatic sense is one that depends in part on "facts about the interests, beliefs or other features of the psychology of those providing or receiving the explanation [or] the 'context' in which the explanation occurs".

A non-pragmatic explanation is thus one that doesn't depend on such things. Instead, it's solely a matter of objective explanatory relations-whether they be causal, nomic, metaphysical, or something else-obtaining between facts 'out there in the world'. ${ }^{5}$ A good pragmatic explanation will oftentimes be one that accurately captures (some of) the objective explanatory relations involved, but due to the vagaries of context, the limitation of our knowledge, and various situation-specific demands, the relationship between the two will usually be complicated.

Most philosophers who rely extensively on reasons-talk, however, seem to be after something different. Rather than pragmatic explanations, they are concerned with one or more theoretical roles a given thing or type of thing might play-roles that they at least implicitly take reasons-talk to track. In the case of normative reasons-talk, one of the relevant roles is that of being a source of normative supportwhether it be moral, prudential, epistemic, or something else-and in the case of motivating reasons-talk the relevant roles include that of rationalizing an action or attitude and that of being a premise in practical and theoretical deliberation. What's more, it's standardly assumed not only that (a) the things we regularly cite as reasonswhether normative or motivating-play such roles, but also that (b) for any given role, there's only one kind of thing that plays it.

I've argued elsewhere against the former assumption with respect to normative reasons-i.e. the assumption that the things we cite as normative reasons are themselves sources of normative support (Fogal 2016a; Fogal and Sylvan 2017). More specifically, I've argued that rather than being sources of normative support (a metaphysical role), the things we ordinarily cite as normative reasons merely function as representatives of such sources (a cognitive and communicative

\footnotetext{
${ }^{5}$ I won't be assuming a particular semantics of 'explanation' and cognate terms (including 'because'), though they are plausibly polysemous and/or semantically underspecified. For preliminary discussion, see Jenkins (2008) and Shaheen (forthcoming).
} 
role). In this paper I'll argue that something similar is true of motivating reasons. That is, I'll argue that the things we ordinarily cite as motivating reasons do not themselves rationalize actions or attitudes, but instead merely function as 'representatives' of a larger body of information or facts, and it is this larger body of information that does the real explanatory work.

The plan in what follows is thus to take a closer look at our ordinary thought and talk about motivating reasons, in an effort to better understand how it works. In doing so I aim to vindicate the coherence and utility of our thought and talk about motivating reasons, but also reveal some of its theoretical limitations and liabilities. This is an important first step in understanding whether-and if so, how-such thought and talk should inform or constrain our substantive theorizing. I begin, in $\$ 2$, by distinguishing normative, motivating, and "merely" explanatory uses of 'reason', explaining more fully what unites and what distinguishes them. In $\$ 3$, I focus specifically on the different ways 'reason' is used when talking about motivating reasons, distinguishing between claims concerning (what I call) factual reasons, teleological reasons, and primary reasons. All three are capable of providing distinctive, person-level explanations of agents' actions and attitudes. They achieve this end in different ways, and hence should be distinguished, but this shouldn't obscure the fact that they are characteristically used to answer the same sort of question, and that the answers they provide complement rather than compete with each other. In $\$ 4$, I explain the relevance of the distinction between so-called 'good' and 'bad' cases-i.e., cases where our beliefs and experiences are veridical versus cases where something goes wrong. In $\mathbb{\$} 5$, I discuss complexities arising from the contextual variability and information-sensitivity of motivating reasons-claims. One of the upshots is that ordinary judgments about motivating reasons are at best a partial and defeasible guide to what really matters, and that so-called factualists, propositionalists, and statists are all partly right, as well as partly wrong, when it comes to the question of what motivating reasons are.

\section{The variety and unity of reasons}

It is standard to distinguish between the reasons why something is the case ('explanatory reasons'), the reasons for which or on the basis of which someone does something ('motivating reasons'), and the reasons for someone to do something ('normative reasons'). There are a number of locutions associated with each. Here are three: ${ }^{6}$

\footnotetext{
${ }^{6}$ With respect to motivating reasons, some philosophers rely heavily on judgments concerning 'the reasons for which' people do things. Such phrases are clearly more stilted,
} 
Explanatory (ER): ' $r$ is a/the reason (why) q.'

('The fact that Jim quit is one reason (why) he's broke.')

Motivating (MR): 'S's reason for $\varphi$-ing is that $q /$ to $\psi$ \}.'

('Rachel's reason for going into law is that it pays well.' /

'Rachel's reason for going into law is to make money.')

Normative (NR): ' $r$ is a reason (for $S$ ) to $\varphi$.'

('The fact that it's raining is a reason to stay inside.')

Although such distinctions are widely recognized, there is disagreement over the proper characterization of each and the relationship between them. ${ }^{7}$ Nonetheless, it's commonly thought that a unified analysis can be provided. As Hyman (2015) puts it:

[T] he basic function of a reason is to explain something-in other words, to make something intelligible or understood-and more particularly to explain why something is the case. (134)

On this view all reasons are explanatory reasons, and essentially so. ${ }^{8}$ As we'll see, different 'kinds' of reasons merely differ in terms of what's being explained (the explanandum), how it's being explained (the kind or level of explanation), or what's doing the explaining (the explanans).

(ER)-sentences are standardly taken to be doubly 'factive': the fact that Jim quit his job, for example, can't be a reason he's broke if he didn't in fact quit, or if he's not actually broke. Similarly for (MR)-sentences containing 'that'-clauses. ${ }^{9}$ If Rachel's reason for going into law is that it pays well, for instance, it must be the case that Rachel is in fact going into law, and that going into law pays well.

however, and hardly used outside action theory and online grammar forums (at least compared to other relevant phrases). Hence my limited, merely illustrative use of such talk. ${ }^{7}$ In drawing such distinctions it is often implicitly assumed that the count noun 'reason(s)' is polysemous-i.e. that (ER), (MR), and (NR) each involve different but semantically related senses of 'reason(s)'. For further discussion, see Fogal (2016b: 284-288).

${ }^{8}$ This isn't to say that the things that are reasons are essentially explanatory; rather, the claim is that the relational property of being a reason is essentially explanatory. Being a reason is a property that needn't be-and often isn't-essential to the things that have it.

${ }^{9}$ Not everyone agrees, of course. The most prominent naysayer is Dancy (2000), though others concur (see e.g. Drake this volume). Although I mostly side with orthodoxy, the issues here are subtle. For relevant discussion of non-factive readings of normally factive sentences (such as those containing verbs like 'knows' and 'regrets'), see Stokke (2013) and Simons et al. (forthcoming). 
However, unlike (MR)-sentences containing 'that'-clauses, (MR)-sentences containing 'to'-infinitivals are not doubly factive in this way-they can be true even though the eventuality expressed by the infinitival fails to obtain. Just because Rachel's reason for going into law is to make money, for example, it doesn't follow that she actually ends up making money. (Perhaps she ends up switching careers before ever receiving a paycheck.) And the same goes for (NR)-sentences-the fact that it's raining can be a reason to stay inside even if one does not, in fact, stay inside. (It does, however, have to be raining.)

Another way of making the point about the explanatory nature of reasonsclaims is in terms of questions and answers: to be a reason of any kind is, in part, to be an answer to a why-question, or at least to be capable of providing such. Different kinds of reasons can then be distinguished partly in terms of the kinds of why-questions they provide answers to.

It's worth noting that the fact that the count noun 'reason'-along with 'explanation' and 'cause'-systematically pairs with the question word 'why' is not an isolated grammatical phenomenon, but instead part of a general, productive pattern. For there is a wide range of different question words, and nearly all have the same relationship to some other noun as 'why' has to 'reason' (along with 'cause' and 'explanation'). ${ }^{10}$ As Lawrence (2017) notes, the relationship is this: a given use of a question word or phrase in an indicative sentence can be replaced by a definite description employing a count noun corresponding to that question word, and the resulting sentence is felt to be truth-conditionally equivalent to the original. The question word-count noun relationships are summarized in Table 1, and examples of sentences that have two equivalent versions, one using a question word and one using a corresponding noun are provided in (1) below (cf. Lawrence 2017: \$1.3).

Table 1: Relationships between question words and corresponding nouns

Question
how
how many
how much
when
where
why
who
what

${ }^{10}$ Yablo (1996: 281, n. 14) makes a similar observation.

\section{Corresponding Nouns}

way

number

quantity, amount

time, moment, day, year, ...

location, place, position

reason, cause, explanation

person

thing 
(1) a. Quietly is $\{$ how/the way\} Mary entered.

b. Four is $\{$ how many/the number of moons Jupiter has.

c. One cup is \{how much milk is needed/the amount of milk needed\}.

d. Ten p.m. is $\{$ when/the time $\}$ I go to bed.

e. $\{$ Where my bicycle is/The location of my bicycle $\}$ remains to be determined.

f. We'll never know \{why/the reason\} Oscar fled the country.

g. $\{$ Who/The person $\}$ Oedipus married was, tragically, his mother.

h. $\{$ What/The thing $\}$ Harry most desired was his dinner.

Insofar as one understands uses of 'reason(s)' in terms of their role in asking and answering why-questions, it's natural to be suspicious of the significance of the debate over what reasons are. There are at least two reasons for this. First, notice that while some of the nouns corresponding to question words-such as 'person'-may seem to function like ordinary nouns in denoting classes of wellindividuated objects, others — such as 'way' and 'amount'-do not. One might then wonder whether an investigation into the ontology of reasons-in any nontechnical sense of 'reason'-is more like an investigation into the ontology of persons or instead the ontology of ways and amounts.

Secondly, there is a wide range of different 'things' that we cite in answering questions. Even though it may be true that all 'proper' or 'full' answers to questions are expressible as complete declarative sentences, and thus propositional in nature, not all parts of a given answer will be of equal significance, and the parts that are most significant-i.e., the parts most relevant to answering the questionvary in terms of what they are. ${ }^{11}$ This is precisely what we find with talk about reasons. As Alvarez (2009) notes: ${ }^{12}$

When we turn to the question of the ontology of reasons, the first thing that strikes one is that things of many different kinds are said to be reasons. For example, facts, propositions, goals, events, things, states of things (including states of minds), features or aspects of the world, considerations (moral, aesthetic, legal, etc.), states of affairs, absences, etc., are all said to be reasons. So it seems that, despite the familiarity of the concept, reasons [are] not clearly assigned to any particular ontological category. (187)

Many philosophers resist this conclusion-including Alvarez-but I think we

${ }^{11}$ Cf. Lawrence (2017), Chapters 1-2.

${ }^{12}$ Cf. Hyman (2015: 133), who makes the point specifically regarding motivating reasons. 
should accept it. ${ }^{13}$ Again, the key is to sharply distinguish between the use of 'reason(s)' in its ordinary sense - or, rather, senses - and 'reason(s)' in some other, more technical sense. Reasons in the ordinary sense can be understood in broadly functional terms as whatever answers, or is capable of answering, the relevant whyquestion. And it should come as no surprise that lots of different things are capable of doing that. Of course, nothing follows about which kinds of things (if any) play the various theoretical roles that are of primary philosophical interest, such as the role of being a source of normative support or that of rationalizing an action or attitude. What kinds of things play these roles is a further issue, and one to be settled on broadly theoretical—not linguistic-grounds.

The claim that all ordinary uses of 'reason(s)' are explanatory, or that all reasons provide answers to why-questions, is most controversial when it comes to normative reasons. ${ }^{14}$ What, if anything, is it that normative reasons help explain? Three main candidates have been defended. ${ }^{15}$ According to the first, for $r$ to be a normative reason for an agent $S$ to $\varphi$ (where $\varphi$ is some action or attitude) is for $r$ to play a certain role in explaining why $S$ ought to $\varphi$ (Broome 2013). ${ }^{16}$ According to the second, for $r$ to be a normative reason for $S$ to $\varphi$ is for $r$ to play a certain role in explaining why it would be good for $S$ to $\varphi$ (Finlay 2014). And according to the third, for $r$ to be a normative reason for $S$ to $\varphi$ is for $r$ to play a certain role in explaining why there is reason (mass noun)-i.e., pro tanto normative support-for $S$ to $\varphi$ (Fogal 2016a). Unsurprisingly, I'm partial to the latter. On my view, normative reasons (count noun) are to be understood in terms of the role they play as 'sources'-or more generally 'explainers' - of reason, analogously to how pleasures, lights, joys, and troubles (count noun) are to be understood in terms of the role they play as 'sources' of pleasure, light, joy, and trouble (mass noun), respectively. ${ }^{17}$ Just as it would be a mistake to analyse pleasure in terms of

\footnotetext{
${ }^{13}$ As does Hyman (2015: chaps. 5-6). Much of Hyman's view is congenial to my own, and he does an admirable job of concisely criticizing the views of Anscombe, Davidson, and Dancy.

${ }^{14}$ For critical discussion, see Brunero (2013).

${ }^{15} \mathrm{I}$ 'm only considering accounts of normative reasons as (a special kind of) explanatory reasons that are intended to be fully general. Schroeder (2007), for instance, focuses specifically on practical reasons; the possibility of extending his account to epistemic reasons is merely hinted at in footnotes.

${ }^{16}$ Schroeter and Schroeter (2009) defend a related view of reasons as right-makers.

${ }^{17}$ Note that claims concerning what one has most or more reason to do are ubiquitous and not equivalent to the corresponding superlative and comparative claims concerning what one has most or more reasons to do. The same goes for quantitative claims concerning how much reason there is to do something, or threshold-y claims concerning whether there's
} 
pleasures, or light in terms of lights, so it would be a mistake to analyse reason in terms of reasons.

The main point, however, is that given any of the candidates above, we can provide a unified account of both normative and non-normative uses of the count noun 'reason(s)': to be a reason (of any kind) is to be something that helps explain something else. As noted above, different 'kinds' of reasons-normative, motivating, explanatory, and so on-merely differ in terms of what's being explained (the explanandum), how it's being explained (the kind or level of explanation), or what's doing the explaining (the explanans). What distinguishes normative reasons, for example, is partly the kind of explanation involved-mere explanatory reasons are typically causal, while normative reasons are not-and partly their explanandum-what normative reasons help explain are normative facts. A parallel point can be made in terms of questions and answers: normative reasons provide answers to normative questions.

\section{Motivating reasons as explanatory reasons}

Whereas normative reasons are distinguished primarily in terms of what they explain-namely, normative facts-together with the kind of explanation they provide-non-causal-motivating reasons are distinguished primarily in terms of what does the explaining-contentful mental states play an essential roletogether with the kind or level of explanation provided-person-level. To provide an explanation of an agent's action or attitude at the so-called 'personal' level invariably involves appealing to (the contents of) the agent's beliefs, desires, intentions, experiences, and the like. A person-level explanation is distinct from, but compatible with, explanations at other levels, including the subpersonal level (e.g. in terms of lower-level cognitive processes) and the non-personal level (e.g. in terms of neurological activity). ${ }^{18}$ Slightly more fully, a person-level explanation is one that helps make sense of or rationalize the agent's action or attitude, rendering it intelligible in light of how things are or appear to be from the agent's perspective. The relevant kind of explanation will thus be 'folk-psychological' in nature-i.e., an explanation cashed out at least partly and implicitly in folk-psychological terms (beliefs, desires, knowledge, intentions, etc.). This is distinct from, but compatible with, explanations of other kinds, whether they be purely physical, historical,

enough reason to do it. For more on normative reason(s)-talk and the mass/count distinction, see Fogal (2016a) and Fogal and Sylvan (2017).

${ }^{18}$ This point about the compatibility of person-level explanations with explanations at other levels and of other kinds is a common one-cf. Dancy (2000: chap. 8) -though the relationship between them is vexed. 
sociological, teleological, metaphysical, normative, or something else.

There are a number of complications concerning the class of motivating reasons. The first is that the standard label ('motivating') is misleading. Although we can have motivating reasons for belief, for example, it's doubtful that we're actually motivated to have beliefs - at least not in general. The same goes for other reasons-responsive attitudes, including intentions, preferences, and the like.

The second complication is also partly terminological. For as many have pointed out, philosophers have used the term 'motivating reason' in at least two importantly different ways. ${ }^{19}$ According to one standard usage, a motivating reason is a consideration "in light of which", or "for which", or "on the basis of which" one acts or forms an attitude, the sort of thing that plays the role of a premise in practical and theoretical reasoning, and so on. According to another, however, a motivating reason is a mental state, or combination of such states, that helps explain-in the right sort of way-why an agent does something or has some attitude.

Given this unfortunate terminological situation, it might be wise to follow Wallace's (2003) advice and ban the term 'motivating reason' altogether. Because the term has become so entrenched, however, it may be preferable to draw a distinction between two kinds of motivating reasons, and the kinds of claims we use to specify them. Either way, terminology is called for that clearly and unambiguously marks the distinction. In deference to Davidson (1963), I'll call the mental states that explain one's action or attitude 'primary reasons' and reserve the term 'guiding reasons' for the other class of motivating reasons, which are not typically mental states (nor facts about them).

The set of guiding reasons can then be usefully subdivided into two: what I'll call 'factual reasons' and 'teleological reasons'. Factual reasons are expressed by claims of the form ' $S$ 's reason for $\varphi$-ing is that $p$ ', while teleological reasons are expressed by claims of the form ' $S$ 's reason for $\varphi$-ing is to $\psi \cdot{ }^{20}$ Roughly put: a factual reason is a fact the awareness of which helps explain why the agent $\varphi$-s, whereas a teleological reason is a goal or purpose that an agent aims to achieve or promote by $\varphi$-ing, and which thereby helps explain her doing so. ${ }^{21}$ In both cases, however, there are other ways of saying more or less the same thing, including with 'reason (why)' and 'because'/'in order to'. Hence we say things like:

\footnotetext{
${ }^{19}$ For versions of this point, see Darwall (2003), Wallace (2003), Davis (2003), and Setiya (2014).

${ }^{20}$ In talking about 'claims' of different kinds I'll be sliding back and forth between (e.g.) talk of sentences and talk of speech acts. This sloppiness is mostly a matter of convenience. I trust context will be sufficient to disambiguate.

${ }^{21}$ For further discussion of teleological reasons, see Sehon (2016: Part I).
} 
(1) Sasha's reason for leaving was that a storm was coming. (factual)

(1') The reason (why) Sasha left was that a storm was coming.

(1") Sasha left because a storm was coming.

(2) Sasha's reason for leaving was to avoid the storm.

(teleological)

(2') The reason (why) Sasha left was to avoid the storm.

(2") Sasha left in order to avoid the storm.

Note that unlike claims of the form ' $S$ 's reason for $\varphi$-ing is to $\psi$ ', not all claims of the form ' $S$ 's reason for $\varphi$-ing is that $p$ ' specify a reason for an agent's actions or attitudes in the relevant sense. We might say, for example, that Sasha's reason for being late was that there was traffic. That there was traffic explains why Sasha was late, but being late (unlike leaving early) needn't be something Sasha does-it can be something that happens to her. ${ }^{22}$ For present purposes, however, I'll only be concerned with claims where the explanandum (i.e., S's $\varphi$-ing) is an agent's action or attitude. They're the only ones that will count as guiding reasons-claims. ${ }^{23}$

It's worth noting that (1) and (2)-like all factual and teleological reasonsclaims - are specificational sentences. (The same goes for (1') and (2').) According to one standard analysis, specificational sentences are a class of copular sentences where the pre-copular phrase (or subject) functions like a question and the postcopular phrase (or complement) functions as its answer. ${ }^{24}$ Consider, for instance:

What Olle wants is a new guitar. (specificational)

Compare it to the following Q\&A-exchange:

${ }^{22}$ Cf. Setiya (2014) on 'active' versus 'passive' actions.

${ }^{23}$ I'll also be ignoring the variety of different readings of ' $S$ 's reason for $\varphi$-ing is $\{$ that $p /$ to $\psi\}$ ' that are possible given the flexibility and context-sensitivity of the possessive ('S's reason...'). (Hawthorne and Magidor (forthcoming) provide some examples.) A helpful diagnostic: the relevant factual and guiding reasons-claims stand or fall with the corresponding 'reason (why)'- and 'because'/'in order to'-claims, as illustrated by (1)-(1") and (2')-(2'"). They're all different ways of answering the same person-level why-question, where the explanandum is $S$ 's $\varphi$-ing; other readings answer other questions.

${ }^{24}$ For a clear and accessible introduction to specificational sentences-along with a defense of the question-answer analysis-see Lawrence (2017). For discussion of specificational sentences of the form ' $S$ 's $\mathrm{CN}$ is that $p$ ', where $\mathrm{CN}$ is a cognitive nominal like 'belief' or 'desire'-along with some relevant remarks on 'reason(s)'-talk—see Pryor (2007). 
Q: What does Olle want?

A: A new guitar.

The similarities are obvious, and the question-answer analysis of specificational sentences explains why: the subject of a specificational sentence (e.g. 'What Olle wants') presents a question ('What does Olle want?') that the complement ('a new guitar') directly answers. The complement does so by specifying the subject-in this case, what it is that Olle wants.

This stands in contrast with predicational sentences, in which the complement describes or is true of the subject. For example:

What Olle wants is expensive. (predicational)

Specificational and predicational sentences-or, rather, readings of sentences-also differ from equative (or 'generalized identity') sentences. These are ones in which the complement is identified or equated with the subject. For example:

What Olle wants is what I want. (equative)

Much more could be said, but what's important for our purposes is just that guiding reasons-claims of the form ' $S$ 's reason for $\varphi$-ing is that $p /$ to $\psi$ \}' are specificational claims. Their complements ('that $p /$ to $\psi$ ') can thus be understood as providing a direct answer to the what-question associated with the subject ('What is $S$ 's reason for $\varphi$-ing?'), and an indirect answer to the intimately related person-level 'why'-question ('Why is $S$ is $\varphi$-ing?' or 'Why does $S \varphi$ ?'). The latter is achieved by means of the former. In brief, it's because the reason specified by the complement of guiding reasons-claims-i.e., the 'that'-clause in factual reasons claims and 'to'-infinitival in teleological reasons-claims-always corresponds to the content of one of the agent's action-guiding or, more generally, operative mental states. (I say 'corresponds' rather than 'is identical' advisedly; see below.) If Sasha's reason for leaving was to avoid the storm, for example, then we may safely assume she wanted or intended to avoid the storm, and that this desire or intention was operative. Similarly, if Sasha's reason for leaving was that a storm was coming, we may safely assume she believed (and arguably knew) that a storm was coming, and that this belief was operative. (We'll return to this point below.)

To say that a given mental state was 'operative' is to say, in part, that it played a role in explaining why an agent did what she did. For as Davidson emphasized, just because someone did something they wanted to do, it doesn't follow that they did it because they wanted to do it. Something else is needed for the relevant mental state to play a role in explaining the action, though what else is needed is subject to controversy. Davidson himself argued that the relevant mental states must cause 
the action, and in order to count as intentional the action needed to be caused in the 'right way' by those states. Others resist the causal picture. ${ }^{25}$ Nonetheless, there's widespread agreement that whatever the explanatory role is, it has to be of the right kind, and hence incompatible with (among other things) deviant explanatory chains.

It's commonly assumed that there's a close relationship between guiding reasons and normative reasons. Although there's debate over what the relationship is, pretty much everyone agrees it falls short of identity. After all, people who do things they shouldn't do (e.g., kill innocent people) and believe things they shouldn't believe (e.g., that vaccines are dangerous) still do and believe those things for reasons, and those reasons needn't actually provide normative support of any kind for what they do or believe. Even though guiding reasons needn't be normative reasons, however, many philosophers think guiding reasons have to be things (facts, propositions, considerations, whatever) the agent treats as normative reasons in their practical or theoretical deliberation.

The plausibility of this proposal depends on what it is to 'treat' something as a normative reason. If that just means that the consideration plays a certain role in the agent's deliberation or motivational structure in virtue of being (or corresponding to) the content of one of their operative mental states, there's little to quibble with. Oftentimes, however, it's assumed that something more is involved. Some think the agent has to take the consideration to be a normative reason, where taking it to be a normative reason is a matter of believing it to be a normative reason or at least being disposed to respond to it in ways akin to those involved in so believing. But even this might be too much, at least insofar as small children and intelligent non-human animals are capable of doing and believing things for (purely motivating) reasons.

For another possible counterexample, consider a die-hard normative skeptic who is steadfast in her rejection of all things normative, and so doesn't take anything to be a normative reason for anything else, even implicitly. Although she may well treat certain considerations as reasons in the aforementioned sense, that's just for those considerations to figure as (or correspond to) the contents of her operative mental states. It's not obvious why any real or apparent normativity would need to enter into such a picture, however, and so cases like this may cast doubt on any alleged non-trivial necessary connection between normative and guiding reasons. ${ }^{26}$ This would be compatible with there being a close connection

\footnotetext{
${ }^{25}$ Whether mental states are causes is a matter of contention, though mental states might still causally explain even if they aren't causes (cf. McLaughlin 2013).

${ }^{26}$ Lord (forthcoming; chap. 6), replaces the 'taking' requirement with one that requires agents 'conceive' of their motivating reasons as a normative reason. He then proceeds to
} 
between normative and guiding reasons in practice, since most agents who act for reasons may take themselves to be acting on the basis of normative reasons. And if their action is in fact appropriately related to normative reasons, that will of course be a good thing; it'll be a case of what Mantel (2013) calls 'normatively apt action', understood as a kind of achievement. Something similar could then be said of agents who take themselves to believe (intend, etc.) for good reasons, and as a matter of fact do (cf. Lord forthcoming: chaps. 5 and 6). This would nonetheless be a contingent fact about particular agents and their guiding reasons, not one that generalizes to all agents and guiding reasons as such.

A related assumption is that guiding reasons are at least the same kind of thing as normative reasons, since our reasons for doing (believing, intending, etc.) things have to be the sorts of things that are capable of being-though they needn't actually be-normative reasons, and vice versa. ${ }^{27}$ Mantel (2014) calls this the Identity Thesis, and argues against it. Although everyone should agree that we're capable of acting and believing for good reasons, and that normative reasons are in some sense 'good', it's far from clear that the Identity Thesis is needed to do justice to the intuitive thoughts standardly taken to motivate it, as opposed to some weaker, though still systematic, correspondence between them. ${ }^{28}$ After all, if what I've suggested so far is correct, guiding and normative reasons are clearly functionally distinct: whereas normative reasons help explain normative facts, guiding reasons help explain actions and attitudes. And it's not clear why we should expect the sorts of things that perform one role to also (and exclusively) perform the other.

It may be, however, that the kinds of things that we normally cite as agents' reasons using factual reasons-claims-i.e., facts about the world-turn out to be the same kinds of things as normative reasons, or at least normative reasons of a certain (e.g. objective) kind. ${ }^{29}$ But even so, this wouldn't be in tension with my earlier claim that such facts are only explanatorily relevant to an agent's action or attitude insofar as the agent is aware of them, and insofar as the relevant mental states are operative in the relevant circumstances. In addition, it'll remain a further question whether the things we cite as factual reasons are the same kind of thing as the contents of our mental states. Ordinary language is an imperfect guide in

offer a suitably deflationary dispositional account of 'conceptions' that promises to circumvent worries about dogs, children, and die-hard normative skeptics. In order to do so, however, there's a worry that the account ends up being too deflationary.

${ }^{27}$ This is what Dancy (2000) calls the "normative constraint".

${ }^{28}$ See also Wallace (2003).

${ }^{29}$ For some worries, though, see Mantel (2015). 
this respect, since 'that'-clauses can be put to multiple uses. ${ }^{30}$ This includes specifying the content of mental states (e.g. 'John's belief was that p') as well as expressing facts about the world (e.g. 'The fact that $p .$. '), and many of these uses may differ in subtle ways. Similar considerations apply to what is expressed using 'to'-infinitivals. For present purposes, however, I needn't take a firm stand one way or the other concerning the ontological relationship (if any) between guiding reasons, normative reasons, and the content of our mental states.

We're now in a position to better understand the notion of a primary reason. For whereas guiding reasons correspond to the contents of an agent's operative mental states, primary reasons are those mental states (or facts about them). Hence we say things like:

(3) The reason (why) Sasha left was that she thought there was a storm coming.

(3') Sasha left because she thought there was a storm coming.

(4) The reason (why) Sasha left was that she wanted to avoid the storm.

(4') Sasha left because she wanted to avoid the storm.

As the above examples illustrate, there's a close connection between guiding reasons and primary reasons, and-as we'll see in the next section-claims about each are best understood as providing complementary explanations rather than competing ones. Summarily put: primary reasons-claims are used to highlight an agent's contentful mental state(s)-i.e., those that play a certain privileged explanatory role-while guiding reasons-claims are used to highlight the content of those states. What unites the two kinds of claims-and what justifies grouping them under the common label of 'motivating reasons'-is that they are both used to achieve the same end, namely, that of providing distinctive, person-level explanation of agents' actions and attitudes. They achieve this end in different ways, and hence should be distinguished, but this shouldn't obscure the fact that they are characteristically used to answer the same sort of why-question, and that the answers they provide are complementary rather than in competition.

By way of summary, here's a modified chart from Grice (2001) listing the four main 'types' of reasons along with some canonical forms and key features:

\footnotetext{
${ }^{30}$ Cf. Pryor (2007) and Huddleston and Pullum (2002: chap. 11, $\left.\$ \$ 1-4\right)$.
} 


\begin{tabular}{|c|c|c|}
\hline Type of reason & Canonical forms-not exhaustive & Features \\
\hline $\begin{array}{l}\text { (1) Purely } \\
\text { explanatory }\end{array}$ & $\begin{array}{l}\text { 'The reason (why) } A \text { is that } B \text { ' } \\
\text { 'That } B \text { is a reason (why) } A^{\prime} \\
\text { 'A because B' }\end{array}$ & $\begin{array}{l}\text { (a) Factive with respect to 'A' and ' } \mathrm{B} \text { ' } \\
\text { (b) 'Reason' used as count, not mass, noun }\end{array}$ \\
\hline (2) Normative & $\begin{array}{l}\text { 'That } \mathrm{B} \text { is a reason }\left(\text { for } \mathrm{X} \text { ) to } \mathrm{A}^{\prime}\right. \\
\text { 'That } \mathrm{B} \text { is a reason } \mathrm{X} \text { has to } \mathrm{A} \text { ' } \\
\text { 'There is }(\mathrm{a}) \text { reason (for } \mathrm{X} \text { ) to } \mathrm{A} \\
\text { because } \mathrm{B}^{\prime}\end{array}$ & $\begin{array}{l}\text { (a) Factive with respect to ' } \mathrm{B} \text { ' but not 'to } \mathrm{A}^{\prime} \\
\text { (b) 'Reason' used as count and mass noun }\end{array}$ \\
\hline (3) Primary & $\begin{array}{l}\text { 'That X B-s is a reason (why) X A-s' } \\
\text { 'The reason (why) X A-s is that X B-s' } \\
\text { 'X A-s because X B-s' }\end{array}$ & $\begin{array}{l}\text { (a) Factive with respect to 'X A-s' and 'X B-s' } \\
\text { (b) 'Reason' used as count, not mass noun }\end{array}$ \\
\hline $\begin{array}{l}\text { (4) Guiding } \\
\text { (Factual / } \\
\text { Teleological) }\end{array}$ & $\begin{array}{l}\text { ' } \mathrm{X}^{\prime} \text { ' reason for } \mathrm{A} \text {-ing is that } \mathrm{B}^{\prime} \text { / } \\
\text { ' } \mathrm{X} \text { 's reason for } \mathrm{A} \text {-ing is to } \mathrm{B}^{\prime} \\
\text { ' } \mathrm{X} \text { A-s because / in order to } \mathrm{B}^{\prime}\end{array}$ & $\begin{array}{l}\text { (a) Factive with respect to 'X A-s' and 'that } \\
\text { B' but not 'to B' } \\
\text { (b) 'Reason' used as a count, not mass, noun }\end{array}$ \\
\hline
\end{tabular}

\section{Good cases versus Bad cases}

Given the distinction between guiding and primary reasons-claims, it's natural to wonder: why make one type of claim rather than another? The answer: it depends. In the case of teleological vs. primary reasons-claims, there's little of substance separating them-they communicate much the same thing, though in different ways. Again, compare (2) to (4):

(2) Sasha's reason for leaving was to avoid the storm.

(teleological)

(2") Sasha left in order to avoid the storm.

(4) The reason Sasha left was that she wanted to avoid the storm. (primary) (4") Sasha left because she wanted to avoid the storm.

Whereas (2) cites Sasha's goal or purpose, (4) cites Sasha's corresponding directive attitude. However, in using (2) a speaker will normally presuppose what is made explicit in (4) - namely, that Sasha wanted to avoid the storm, and that this desire was operative in the relevant circumstances. ${ }^{31}$ In using (2), then, a speaker implicitly communicates what is explicitly communicated by (4). The main difference is that the focus is on the goal itself, rather than the directive attitude, which is backgrounded. Ditto for (2") and (4").

The relationship between factual and primary reasons is similar, subject to a caveat to be discussed later. For just as (2) implicitly communicates what is explicitly communicated by (4), so (1) implicitly communicates what is explicitly

\footnotetext{
${ }^{31}$ Here and elsewhere I rely on an intuitive notion of speaker presupposition and related notions. There are a number of important subtleties that I lack the space to discuss. For an introduction to presupposition (and its failure), see Beaver and Geurts (2014). For further-and particularly relevant-discussion of presupposition and factive constructions, see Simons et al. (forthcoming).
} 
communicated by (3):

(1) Sasha's reason for leaving was that a storm was coming.

(1") Sasha left because a storm was coming.

(factual)

(3) The reason Sasha left was that she \{thought/knew a storm was coming.

(3") Sasha left because she $\{$ thought/knew a storm was coming. (primary)

In using (1), a speaker will normally take it for granted that Sasha believed-and indeed knew-that there was a storm coming, and that this belief was operative in the circumstances leading to her action. Whether knowledge of the relevant fact is strictly required in order for factual reasons claims to be felicitous is subject to debate. ${ }^{32}$ It's nonetheless plausible that in order for an agent's reason to be that $p$ that subject must have a (presumably justified) true belief that is connected to the fact that $p$ in the right sort of way, and that this will normally suffice for knowledge.

Notice that in using (1) it will normally be taken for granted not just that Sasha believed there was a storm coming, but also that she wanted to avoid it, and that this desire-like the belief-was operative. Similarly, with (2) it will be assumed not just that Sasha wanted to avoid the storm, but also that she believed a storm was coming, and that this belief-like the desire-was operative. The presence of the relevant action-guiding belief and desire will thus normally be presupposed by the use of both (1) and (2). The main difference, again, is that whereas factual reasons-claims like (1) highlight the content of an operative cognitive state (belief, knowledge, etc.), teleological reasons-claims like (2) highlight the content of an operative directive state (desire, intention, etc.). I say 'highlight' rather than 'identify' in order to remain neutral on the exact relationship between the fact/goal cited in (1)/(2) and the content of the agent's mental states. As noted above, I do not assume that the relationship is one of identity. I only claim that there is a systematic correspondence, and that in using guiding reasonsclaims we exploit this fact for the purposes of communication.

The other main difference between teleological and factual reasons-claims (noted at the outset) is that factual reasons-claims are normally (doubly) factive. ${ }^{33}$ The claim below, for example, will be acceptable only if it is, in fact, my birthday-

${ }^{32}$ Williamson (forthcoming), Hawthorne and Magidor (forthcoming), and Hyman (2015) think knowledge is required. Locke (2015) demurs, appealing to fake barn-style cases.

${ }^{33}$ The 'normally' hedge is in recognition of the fact that there are non-factive uses of $(5) /(6)$ below-albeit ones that merit special treatment. For the purposes of this paper I'm focusing on the central, factive use. 
which we may suppose it is-and my grandma is aware of that fact:

(5) Grandma's reason for sending me a card is that it's my birthday.

Likewise, if Bob isn't Superman—which, we may suppose, he's not—then it would be unacceptable to say:

(6) \#Bob's reason for believing that he can fly is that he's Superman.

This illustrates a general pattern: in so-called 'Good' cases-like that involving Grandma-where the relevant agent's beliefs and experiences are veridical and appropriately connected to the facts, factual reasons-claims are good. But in 'Bad' (or 'Error') cases-like that involving Bob-where the relevant agent's beliefs and experiences are not veridical or not appropriately connected to the facts, factual reasons-claims are bad. Bad cases include cases of hallucination and illusion, as well as more humdrum cases of false belief, whether justified or not.

Notice, however, that in both Good and Bad cases we have the option of citing the subject's contentful mental states in explaining their actions or attitudes. ${ }^{34}$ For example:

(7) The reason Grandma sent me a card is that she believes it's my birthday.

(7') Grandma sent me a card because she believes it's my birthday

(8) The reason Bob believes he can fly is that he believes he's Superman.

(8') Bob believes he can fly because he believes he's Superman.

Accordingly, in Good cases, where the subject's operative doxastic attitudes are true and appropriately connected to the facts, we have a choice between the two kinds of explanatory claims, whereas in the Bad case, where the subject's operative doxastic attitudes are not true, we don't-the factual reasons-claim is infelicitous. This is to be expected given that factual reasons-claims-unlike teleological reasons-claims-are normally replaceable with backwards-looking (or retrospective) 'because'-claims, and 'because'-claims are generally taken to be factive with respect to both the explanans and explanandum. Teleological reasonsclaims, in contrast, are generally replaceable with forward-looking (or prospective)

${ }^{34}$ In the good case we have intermediate options available. For example, instead of citing worldly facts or states of belief and desire, we might cite facts about appearances:

$\left(^{*}\right)$ The reason Gail believes the animal is a zebra is that it appears to have stripes.

$\left({ }^{* *}\right)$ Gail believes the animal is a zebra because it appears to have stripes. 
'in order to'-claims, and these are not factive with respect to the explanans. ${ }^{35}$

Although in Good cases, unlike Bad cases, we have a choice of explanatory locution, factual reasons-claims are nonetheless generally favoured over primary reasons-claims-i.e., ones that cite the agent's mental states. Why? A simple answer suggests itself: because factual reasons-claims are more informative than primary ones. In particular, factual reasons-claims communicate implicitly what primary reasons-claims communicate explicitly-namely, that the agent has an operative attitude with a certain content-while also communicating something extra about the world. Given this, there is a fairly straightforward, broadly Gricean story to tell about why factual reasons-claims are commonplace, and why they should be seen as offering explanations that complement rather than compete with explanations provided by primary reasons-claims. It's not an either-or. Both provide person-level, folk-psychological explanations of the agent's action or attitude, but whereas primary reasons-claims provide such explanations directly by citing the agent's operative mental states, factual reasons-claims (like teleological ones) do so indirectly by citing a fact the agent is aware of (or, in the case of teleological reasons, a goal she has), thereby presupposing-without citing-the relevant mental states. The latter conveys everything the former does, and more besides. Hence the increased informativeness and conversational relevance (in Good cases) of factual reasons-claims, which can be understood as providing hybrid worldly/folk-psychological explanations rather than just folk-psychological ones like primary reasons-claims.

It's worth emphasizing that the choice between explanatory items and locutions is a general feature of our explanatory practice. ${ }^{36}$ Suppose, for example, that a bridge collapses and you want to know why. I might tell you about the physical or structural properties of the bridge immediately prior to the collapse, and why it was in a weakened state, or I might instead tell you about how it was originally built, what the engineers did wrong, and how the condition of the bridge degraded over time. The former explanation is more proximal while the latter is more distal, but both serve the general purpose of explaining why the bridge

\footnotetext{
${ }^{35}$ Not all 'because'-claims are backwards-looking. Jenkins and Nolan (2008), for example, provide a litany of examples in which something that occurs at $t_{1}$ is explained by appealing to something which occurs at a later time $t_{2}$. E.g.:

(1) I am tidying my flat today because my brother is coming to visit tomorrow. As with other 'because'-claims, such explanations are generally factive: in order for (1) to be true, for example, it has to be that my brother is in fact coming to visit tomorrow. (Again, there are subtleties concerning factivity that I'm ignoring.) There are also synchronic 'because'-claims, as metaphysical explanations (among others) make clear. ${ }^{36}$ See, for example, Lewis (1986).
} 
collapsed. It would be a mistake to think they are somehow in competition with each other qua explanations, even though in some contexts one might be more appropriate or relevant than the other, depending on our particular interests and background information.

\section{Contextual Variability and Explanatory Clusters}

I take it to be fairly obvious that the presence of the relevant attitudes is normally presupposed by guiding reasons-claims (or, rather, by the speaker making such claims). But in case evidence is needed: when making such claims it's normally infelicitous to deny the presence of the relevant attitudes. For example:

$\left(1^{*}\right)$ \#Sasha's reason for leaving was that a storm was coming, even though she didn't $\{$ know/believe $\}$ that a storm was coming.

$\left(1^{* *}\right)$ \#Sasha left because a storm was coming, even though she didn't

$\{\mathrm{know} / \mathrm{believe}\}$ that a storm was coming.

$\left(2^{*}\right)$ \#Sasha's reason for leaving early was to avoid the storm, even though she didn't \{want/intend $\}$ to avoid it - that wasn't her aim. ${ }^{37}$

$\left(2^{* *}\right)$ \#Sasha left in order to avoid the storm coming, even though she didn't \{want/intend $\}$ to avoid it.

The infelicity of $\left(1^{*}\right)$ and $\left(2^{*}\right)$ is to be expected given that motivating reasonsclaims characteristically provide answers to person-level, folk-psychological whyquestions. By explicitly denying the presence of the relevant mental state, claims like $\left(1^{*}\right)$ and $\left(2^{*}\right)$ fail to answer to the relevant kind of question. ${ }^{38}$

It's worth emphasizing that given what we know about the nature of our explanatory practices in general, in which surprisingly few facts usually suffice-for communicative purposes, not metaphysically-to explain complicated facts or events, it should come as little surprise that in making guiding reasons-claims we take certain other facts for granted. Indeed, pretty much all ordinary explanatory

${ }^{37}$ I include the additional material at the end to force what Condoravdi and Lauer (2016) call the 'strong' (or 'operative') rather than the 'weak' reading of verbs like 'want'.

${ }^{38}$ At least in the absence of special circumstances. Note also that the only way to felicitously continue $\left(1^{* *}\right)$-and similar sentences starting with 'the reason Sasha left' instead of 'Sasha's reason'-will turn it into a non-personal explanatory claim. (Thanks to Olle Risberg for this observation.) For example:

$\left(1^{* * *}\right)$ Sasha left because there was a storm coming. She wasn't actually aware of the storm, but she somehow always gets sick before the weather turns foul. 
claims - ' $A$ explains $B$ ', ' $B$ because $A$ ', etc.- -are made, and hence to be evaluated, relative to a large body of background information or facts, and the cited fact alone will rarely if ever fully explain the explanandum. The things we cite as, explanansi.e. as the things that do the explaining (e.g. A)-are thus almost always merely part, and oftentimes a very small part, of a much larger body of information or facts, and it's the latter that constitutes the 'full' explanation of the explanandum (e.g. B), if anything does. ${ }^{39}$

Note that we typically have a certain amount of leeway in deciding which explanatorily relevant facts/events/states/goals/etc. to cite as reasons in providing an explanation of something, and which to merely treat as part of the informational background. The promotion of explanatorily relevant facts (etc.) to status of explicit explanans is thus partly up to us, with the choice being constrained-but not always determined-by what happens to be particularly salient or otherwise relevant, among other things. (That's not to say that the explanatory relevance of those facts is up to us; it's not.)

Suppose, for example, that Gail is at the zoo and sees an animal with black and white stripes. She recognizes the pattern as one that is characteristic of zebras, and so comes to believe the animal is a zebra. Given this background information, it would be acceptable to say either of the following:

(9) Gail's reason for believing the animal is a zebra is that it has stripes.

(9') Gail believes the animal is a zebra because it has stripes.

(10) Gail's reason for believing the animal is a zebra is that zebras have stripes. (10') Gail believes the animal is a zebra because zebras have stripes.

But despite the felicity of (9) and (10), it would be decidedly odd to cite both facts individually as guiding reasons:

(11) \#One of Gail's reasons for believing the animal is a zebra is that it has stripes, and another is the fact that zebras have stripes.

(11') \#'Gail believes the animal is a zebra because it has stripes, and also because zebras have stripes.

Intuitively, (11) is guilty of something like explanatory 'double counting', since neither fact cited is explanatorily relevant on its own, independently of the other.

${ }^{39}$ This is oversimplifying, since there's usually no such thing as the full explanation of something-cf. Lewis (1986). Here, as elsewhere, I'm ignoring additional complexities. 
Instead, it's only when the two facts are (at least implicitly) taken together that any amount of explanatory 'oomph' is generated. Hence the acceptability of citing the facts collectively as her reason:

(12) Gail's reason for believing the animal is a zebra is that it has stripes like a zebras does.

(12') Gail believes the animal is a zebra because it has stripes like a zebras does.

The same sort of contextual variability arises with teleological reasons-claims, as well as primary reasons-claims. To illustrate the latter: while (3) and (4) above are felicitous, citing both mental facts individually as reasons is not:

(13) \#One reasons (why) Sasha left is that she thought a storm was coming, and another was that she wanted to avoid it.

(13') \#Sasha left because she thought a storm was coming, and also because she wanted to avoid it.

As before, (13) is guilty of something like explanatory double counting, with neither psychological fact being explanatorily relevant on its own. Instead, it's only when both are taken together-whether explicitly or not-that explanatory relevance is achieved. ${ }^{40}$ The full grounds of explanatory relevance thus belong (as before) to a larger cluster of facts that includes both, and more besides.

The moral: claims about motivating reasons, like nearly all explanatory claims, are highly context-sensitive and influenced by pragmatic considerations. We should therefore be wary of assigning undue significance to any particular use of sentences of the form ' $S$ 's reason for $\phi$-ing is \{that $p /$ to $\psi$ \}'. Instead, the things-facts, states, goals, propositions, etc.- - that we cite as guiding and primary reasons are best understood as functioning as (something like) representatives of explanatory clusters, where an 'explanatory cluster' is a body of information or facts that taken as a whole-and only taken as whole-is explanatorily relevant to some action or attitude. For reasons having to do with communicative efficiency as well as our informational limitations, we rarely if ever mention entire clusters. Instead, we single out one or two particularly relevant or accessible representatives and ascribe responsibility to them. As a consequence, whatever it is that we decide to single out in a particular context should not, by itself, be taken as indicative of anything

\footnotetext{
${ }^{40}$ As before it would be fine to cite the facts collectively as a primary reason-something Davidson was sensitive to. See also Hornsby (2008: 246, n. 4).
} 
metaphysically special. In a different conversational context-one differing in terms of shared background information, preceding discourse, etc.- some other representative of the very same cluster that explains the relevant action or attitude might be more salient, or otherwise relevant, and hence be referenced instead. ${ }^{41}$

On the picture suggested so far, it is natural to expect ordinary explanatory thought and talk to be governed by something like the following general norm (cf. Swanson 2010):

\section{USE GOOD REPRESENTATIVES}

When you ascribe some explanatory responsibility for $A$ to an explanatory cluster relevant to $A$, use good representatives of that cluster for the purposes at hand.

The 'goodness' of a potential representative will be a function of the amount of information it provides-either directly or indirectly, given the background information-about the relevant explanatory cluster, as well as the economy with which it provides that information. Ceteris paribus, the better a representative satisfies this dual constraint, the better a representative it will be. The relative 'goodness' of a potential representative will thus vary from context to context-and even within a context-depending on the interests of and background information shared by the conversational participants, including whether (and if so, which) other representatives have already been used. In the case of motivating reasonsclaims, however, there's an important further constraint-the relevant cluster(s) have to be capable of providing a rationalizing, person-level explanation, and the representatives we select have to be appropriately related to such.

The view of reasons as representatives-i.e., the view that the things we ordinarily cite as reasons function as representatives of explanatory clusters-thus has a ready explanation of the acceptability of (9)-(10) and (12) as well as the defectiveness of (11) and (13). For in each case there are at least two facts belonging to the same explanatory cluster, either of which is suitable on its own to serve as a good representative for the purposes at hand. (Hence the acceptability of (9) and (10).) However, once one of the relevant facts is cited as a reason-and hence used as a representative-it robs the other of its representative role. To nonetheless cite both facts individually as reasons would thus be misleading, since

${ }^{41}$ Since this is a general feature of our explanatory practice, it shouldn't be surprising that it's true not just of guiding reasons-claims but also of normative reasons-claims as well as of causal claims. For defence of the latter two points, see Fogal (2016a) and Swanson (2010) respectively. The discussion here and immediately below generalizes observations made by Swanson in the case of causal talk, and mirrors the discussion in Fogal (2016a: $\$ 4$ ). 
it would wrongly imply that the facts belong to separate explanatory clusters. (Hence the defectiveness of (11) and (13).) In contrast, it's perfectly fine to cite both facts collectively as a reason, since together they function as a good representative. (Hence the acceptability of (12).)

One upshot is that rather than trying to explain away the variability in what we cite as motivating reasons or the kind of linguistic constructions we use, we should embrace it. Though the means vary, the goal remains the same: to provide a person-level, folk-psychological explanation of an agent's action or attitude. While in many contexts it might make sense to cite a particular worldly (or non-mental) fact in doing so-one the agent is aware of and responsive to-in other contexts it might make more sense to cite the agent's mental states, and in still others it might be most useful to cite the content of those states. Indeed, we might have a choice: all that's needed is something - a fact, state, proposition, goal, whateverthat can serve as a good representative of one or more explanatory cluster(s) relevant to the case at hand, and there may be equally good representatives, or equally good explanatory clusters. Different ways of using 'reason' can all be seen as ways of focusing on different aspects of those clusters, and hence different kinds of things. What unifies our motivating reasons-claims is the role of 'reason' in providing person-level explanations, not any common underlying ontology. And even though the acceptability of such claims will vary depending on the contextually relevant body of information, the underlying facts that we are (or at least should be) primarily interested in-what I've called the 'explanatory clusters'-remain constant.

None of this is to deny that there will usually be fairly severe constraints on eligible referents of 'reasons(s)' in particular contexts or in particular linguistic constructions-as with explanatory claims in general, not just anything goes. But given that the relevant explanatory clusters are often complex and varied, we should expect there to be variability in terms of both (a) what particular thing is cited as a reason and (b) the kind of thing it is that gets cited. Instead of assigning undue significance to any particular judgment (or set of judgments) involving a motivating use of 'reason(s)', then, we as theorists should focus our attention on the nature, composition, and relevance of explanatory clusters - the real sources of explanatory oomph-that motivating reasons only imperfectly point to.

\section{Conclusion}

Insofar as we're interested in providing a person-level explanation of an agent's action or attitude, we need information about their mental life. In particular, we need to know something about which mental states are (or were) operative. This information provides us with a proximal person-level explanation of the agent's action or attitude (cf. Wedgwood 2017: chap. 7). But it would be a mistake to

think that this is the only kind of motivating reasons-explanation we can or should 
provide. On the contrary, given what I've argued for, we should expect there to be plenty of good motivating reasons-explanations that cite things other than mental states, whether they be facts, propositions, objects, states of affairs, or something else. It's true-and important - that in order to provide an explanation of the right kind (i.e., person-level), such explanations require the presence of the relevant mental states. But sometimes we're interested in acquiring or providing a fuller and more distal explanation of an agent's action or attitude, and we can do so by appealing to certain facts that the agent is aware of. These are the contexts in which factual reasons-claims are most natural. Other times, however, we're interested primarily in what exactly an agent wants or intends to do, and hence in the content of their relevant directive attitude. These are the contexts in which teleological reasons-claims are most natural. In neither case is there anything wrong or superfluous with the claim in question, and it's a mistake to think either is in direct competition with primary reasons-claims that cite the mental states themselves. ${ }^{42}$ The variety of claims we have at our disposal simply reflects the variety of our possible explanatory interests.

This ecumenical conclusion shouldn't obscure the point, however, that primary reasons are in a meaningful sense primary when it comes providing person-level explanations. For everyone should agree that facts about contentful (and operative) mental states are essential ingredients in providing proximal folk-psychological explanations, and their presence is always presupposed by factual and teleological reasons-claims. It's in this sense-but this sense only-that primary reasons are primary.

\footnotetext{
${ }^{42}$ Contra Turri (2009).
} 


\section{Bibliography}

Alvarez, M. (2009). How many kinds of reasons? Philosophical Explorations, 12(2), 181-193

Beaver, D., \& Geurts, B. (2014). Presupposition. In E. Zalta (Ed.), The Stanford Encyclopedia of Philosophy (Winter 2014 Edition).

Bromberger, S. (1966). Questions. The Journal of Philosophy, 63(20), 597-606.

Broome, J. (2013). Rationality through Reasoning. Wiley Blackwell.

Brunero, J. (2013). Reasons as Explanations. Philosophical Studies, 165(3), 805-824.

Condoravdi, C., \& Lauer, S. (2016).

Anankastic conditionals are just conditionals. Semantics and Pragmatics, 9(8), 1-69.

Cross, C., \& Roelofsen, F. (2016). Questions. In The Stanford Encyclopedia of Philosophy (Spring 2016 Edition).

Dancy, J. (2000). Practical Reality. Oxford University Press.

Darwall, S. (2003). Desires, Reasons, and Causes. Philosophy and Phenomenological Research, 67(2), 436-443.

Davidson, D. (1963). Actions, Reasons, and Causes. The Journal of Philosophy, 60, 685700.

Finlay, S. (2014). Confusion of Tongues: A Theory of Normative Language. Oxford University Press.

Fogal, D. (2016a). Reasons, Reason, and Context. In E. Lord, \& B. Maguire (Eds.), Weighing Reasons. Oxford University Press, 74-103.

Fogal, D. (2016b). Review of Stephen Finlay's Confusion of Tongues: A Theory of Normative Language. Ethics, 127(1), 281288.

Fogal, D., \& Sylvan, K. (2017). Contextualism about Epistemic Reasons. In J. J. Ichikawa (Ed.), The Routledge Handbook of Epistemic Contextualism. Routledge.
Grice, H. (2001). Aspects of Reason. Oxford University Press.

Hawthorne, J., \& Magidor, O. (forthcoming). Reflections on Reasons . In D. Star (Ed.), The Oxford Handbook on Reasons and Normativity. Oxford University Press.

Hempel, C. (1965). Aspects of Scientific Explanation and Other Essays in the Philosophy of Science. The Free Press.

Hornsby, J. (2008). A Disjunctive Conception of Acting for Reasons. In A. Haddock and F. Macpherson (Eds.) Disjunctivism: Perception, Action, Knowledge. Oxford Univeristy Press, 244-261.

Huddleston, R., \& Pullum, G. K. (2002). The Cambridge Grammar of the English Language. Cambridge University Press.

Hyman, J. (2015). Action, Knowledge, and Will. Oxford University Press.

Jenkins, C. S. (2008). Romeo, René, and the Reasons Why: What Explanation Is. Proceedings of the Aristotelian Society, 108, 6184.

Jenkins, C. S., \& Nolan, D. (2008). Backwards explanation. Philosophical Studies, 140(1), 103-115.

Lawrence, R. (2017). Nominalization, Specification, and Investigation. UC Berkeley.

Lewis, D. (1986). Causal Explanation . In D. Lewis (Ed.), Philosophical Papers, Vol. II. Oxford University Press, 214-240.

Locke, D. (2015). Knowledge, Explanation, and Motivating Reasons. American Philosophical Quarterly, 52(3), 215-232.

Lord, E. (forthcoming). The Importance of Being Rational. Oxford University Press.

Mantel, S. (2013). Acting for reasons, apt action, and knowledge. Synthese, 190(17), 3865-3888.

Mantel, S. (2014). No reason for identity: on the relation between motivating and normative reasons. Philosophical Explorations, 17(1), 49-62. 
Mantel, S. (2015). Worldly Reasons: An Ontological Inquiry into Motivating Considerations and Normative Reasons. Pacific Philosophical Quarterly, DOI: 10.1111/papq.12094.

McLaughlin, B. (2013). Why Rationalization Is Not a Species of Causal Explanation. In G. D'Oro, \& C. Sandis (Eds.), Reasons and Causes: Causalism and anti-Causalism in the Philosophy of Action. Palgrave McMillan, 97.123.

Paul, L., \& Hall, N. Causation: A User's Guide. Oxford University Press.

Pryor, J. (2007). Reasons and that-clauses. Philosophical Issues, 17(1), 217-244.

Pryor, J. (2014). There is Immediate Justification. In M. Steup (Ed.), Contemporary Debates in Epistemology. Blackwell, 202-221.

Roberts, C. (2012). Information Structure in Discourse: Towards and Integrated Formal Theory of Pragmatics. Semantics \& Pragmatics, 5(6), 1-69.

Roberts, C. (2012). Information Structure: Afterword. Semantics and Pragmatics, 5(7), 119.

Schroeder, M. (2007). Slaves of the Passions. Oxford University Press.

Sehon, S. (2016). Free Will and Action Explanation: A Non-Causal, Compatibilist Account. Oxford University Press.

Setiya, K. (2014). What is a reason to act? Philosophical Studies, 167(2), 221-235.
Shaheen, J. L. (forthcoming). Ambiguity and explanation. Inquiry.

Simons, M., Beaver, D., Roberts, C., \& Tonhauser, J. (forthcoming). The Best Question: Explaining the Projection Behaviour of Factives. Discourse Processes. Smith, M. (2003). Humeanism, Psychologism, and the Normative Story. Philosophy and Phenomenological Research, 67(2), 460-467.

Stokke, A. (2013). Protagonist Projection. Mind \& Language, 28(2), 204-232.

Swanson, E. (2010). Lessons From The Context Sensitivity of Causal Talk. The Journal of Philosophy, 107(5), 221-242.

Turri, J. (2009). The Ontology of Epistemic Reasons. Noûs, 43(3), 490-512.

van Fraassen, B. (1980). The Scientific Image. Oxford University Press.

Wallace, R. J. (2003). Explanation, Deliberation, and Reasons. Philosophy and Phenomenological Research, 67(2), 429-435.

Wedgwood, R. (2017). The Normativity of Rationality. Oxford University Press.

Williamson, T. (forthcoming). Acting on Knowledge. In J. A. Carter, E. Gordon, \& B. Jarvis (Eds.), Knowledge-First. Oxford University Press.

Woodward, J. (2014). Scientific Explanation. In E. N. Zalta (Ed.), The Stanford Encyclopedia of Philosophy (Spring 2017 Edition).

Yablo, S. (1996). How in the World? In C. Hill (Ed.), Philosophical Topics. University of Arkansas Press, 255-286. 